CLINICAL STUDY

\title{
Elevated LH predicts ischaemic heart disease events in older men: the Health in Men Study
}

\author{
Zoë Hyde ${ }^{1,2}$, Paul E Norman ${ }^{3}$, Leon Flicker ${ }^{1,2}$, Graeme J Hankey ${ }^{2,4}$, Kieran A McCaul ${ }^{1,2}$, Osvaldo P Almeida ${ }^{1,5,6}$, \\ $\mathrm{S}$ A Paul Chubb ${ }^{2,7}$ and Bu B Yeap ${ }^{2,8}$ \\ ${ }^{1}$ Western Australian Centre for Health and Ageing (M570), Centre for Medical Research, Western Australian Institute for Medical Research, ${ }^{2}$ School of \\ Medicine and Pharmacology and ${ }^{3}$ School of Surgery, University of Western Australia, 35 Stirling Highway, Crawley, Western Australia 6009, Australia, \\ ${ }^{4}$ Department of Neurology, Royal Perth Hospital, GPO Box X2213, Perth, Western Australia 6001, Australia, ${ }^{5}$ School of Psychiatry and Clinical \\ Neurosciences, University of Western Australia, Perth, Western Australia 6009, Australia, ${ }^{6}$ Department of Psychiatry, Royal Perth Hospital, Perth, \\ Western Australia 6001, Australia, ${ }^{7}$ PathWest, Department of Biochemistry, Fremantle Hospital, PO Box 480, Fremantle, Western Australia 6959 , \\ Australia and ${ }^{8}$ Department of Endocrinology and Diabetes, Fremantle Hospital, Fremantle, Western Australia 6959, Australia
}

(Correspondence should be addressed to Z Hyde at Western Australian Centre for Health and Ageing; Email: zoe@sexologyresearch.org; or B B Yeap; Email: byeap@cyllene.uwa.edu.au)

\begin{abstract}
Context: Hypogonadism in men is associated with insulin resistance, elevations in pro-inflammatory cytokines and fibrinogen, and an atherogenic lipid profile. However, it is uncertain whether the age-related decline in testosterone is associated with ischaemic heart disease (IHD) events.

Objective: To determine whether testosterone and its associated hormones, sex hormone-binding globulin (SHBG) and LH, predict IHD events in older men.

Design: Prospective cohort study.

Methods: Between 2001 and 2004, 3637 community-dwelling men aged 70-88 years underwent a clinical assessment of cardiovascular risk factors and biochemical assessment of testosterone, SHBG and LH. Free testosterone was calculated using mass action equations. Participants were followed until December 2008 using electronic record linkage to capture IHD events (hospital admission or death). Results: Mean follow-up was 5.1 years. During this period, 618 men (17.0\%; 95\% confidence interval (CI) $15.8,18.3 \%$ ) experienced an event, of which 160 were fatal. Men with higher baseline total or free testosterone levels experienced fewer IHD events (hazard ratio $(\mathrm{HR})=0.89 ; 95 \%$ CI 0.82, 0.97 and $\mathrm{HR}=0.86 ; 95 \% \mathrm{CI} 0.79$, 0.94 for each one s.D. increase in total and free testosterone respectively). These associations were maintained after adjustment for age and waist:hip ratio but did not persist after adjustment for prevalent IHD or other cardiovascular risk factors. SHBG was not associated with IHD events. In contrast, higher LH levels were associated with reduced event-free survival in both univariate ( $\mathrm{HR}=1.15 ; 95 \%$ CI 1.08, 1.22) and adjusted analyses ( $\mathrm{HR}=1.08 ; 95 \%$ CI 1.01, 1.15). Conclusions: Dysregulation of the hypothalamic-pituitary-gonadal axis may be a risk factor for IHD. Further studies of men with either elevated LH or low testosterone are warranted.

European Journal of Endocrinology 164 569-577
\end{abstract}

\section{Introduction}

Ischaemic heart disease (IHD) is a leading cause of mortality and morbidity worldwide, accounting for $12 \%$ of deaths in 2004 (1). Currently ranked fourth, IHD is expected to become the second largest contributor to the global burden of disease by 2030 (1). Mortality rates for IHD vary across the globe, but a consistent male-to-female ratio of $\sim 2: 1$ is observed (2). Behavioural differences between the sexes, such as higher rates of smoking in men, may partly account for this discrepancy but are insufficient to explain it. Some have therefore hypothesised a role for sex hormones in the aetiology of IHD (3).

Sex hormones appear to mediate several key sex differences in the cardiovascular system. Compared with men, women have higher resting heart rates and a longer QT interval (4). The latter emerges at puberty and appears to be influenced by androgens; administration of testosterone shortens the QT interval in both sexes $(5,6)$. Similarly, sex differences in lipids and blood pressure develop at puberty. Both systolic and diastolic blood pressures are higher in men until $\sim 60$ years of age (7). Women have greater high-density lipoprotein (HDL) levels throughout the lifespan and less lowdensity lipoprotein (LDL) until menopause (8). The latter actions suggest that the male hormonal milieu could be detrimental to cardiovascular health, but favourable effects of androgens are also observed.

Testosterone levels correlate inversely with arterial stiffness, intima-media thickness and aortic diameter 
(9, 10), predictors of cardiovascular events. Male hypogonadism is associated with insulin resistance, increased production of pro-inflammatory cytokines, elevated fibrinogen and an atherogenic lipid profile (11). Conversely, testosterone replacement increases antioxidant levels, and improves the cytokine profile, insulin sensitivity and abdominal obesity (12-14). These observations suggest a more complex role for testosterone and are consistent with the hypothesis that androgen deficiency plays a role in the pathogenesis of IHD.

Testosterone is the major circulating androgen in males and is almost entirely bound to sex hormonebinding globulin (SHBG) and albumin. Less than 2\% circulates unbound or 'free'. The free and albumin-bound portion is generally considered most active in target tissues. Testosterone levels reach a peak in early adulthood and then decline by 1-2\% per year thereafter (15), although the clinical significance of this is uncertain. Epidemiological studies investigating whether testosterone levels are associated with IHD are conflicting. Some have reported that low testosterone predicts death from IHD (16), while others have found no association (17), or that higher testosterone levels are associated with increased IHD mortality (18). However, variability in sample size, duration of follow-up, age range and ability to capture endpoints with certainty limit the ability to draw conclusions from the data. Additionally, as far as we are aware, no prospective studies have explored the relationship between gonadotrophins and IHD in older men.

We therefore designed this study to explore associations between sex hormones and IHD in a large cohort of community-dwelling men aged 70-88 years at baseline, using electronic record linkage. We hypothesised that men with lower testosterone and higher LH levels would be more likely to experience an IHD event (either a hospital admission or death) during a follow-up period of up to 7 years.

\section{Participants and methods}

\section{Study population}

The Health in Men Study (HIMS) is a population-based study of men living in Perth, Western Australia, originally recruited for a trial of screening for abdominal aortic aneurysm (AAA) (19). Participants were randomly selected from the electoral roll (enrolment to vote being compulsory). Between 1996 and 1999 (wave 1, W1), 12203 mostly Caucasian men aged 65 years and older attended a clinic and completed a questionnaire, providing a range of demographic and risk factor data. Approximately, 5 years later, 10940 surviving men were invited to a follow-up study. Between 2001 and 2004 (wave 2, W2), 5585 men completed a second questionnaire, and 4263 of these attended a clinic. Early morning blood samples were obtained from 4249 clinic attendees. The human research ethics committee of the University of Western Australia approved the study.

\section{Laboratory methods}

Blood samples were collected at W2 between 0800 and $1030 \mathrm{~h}$ to minimise circadian variation. Serum was prepared immediately following phlebotomy and stored at $-80{ }^{\circ} \mathrm{C}$ until assayed. Biochemical assays were performed in the Biochemistry Department, PathWest, Royal Perth Hospital, Western Australia, as reported previously (20). Serum total testosterone, SHBG and LH were determined by chemiluminescent immunoassays on an Immulite 2000 analyser (Diagnostic Products Corp. Biomediq, Doncaster, Australia). Between-day imprecision was $11.2 \%$ at $7.2 \mathrm{nmol} / \mathrm{l}$ and $8.9 \%$ at $18 \mathrm{nmol} / \mathrm{l}$ for total testosterone; $6.7 \%$ at $5.2 \mathrm{nmol} / \mathrm{l}$ and $6.2 \%$ at $81 \mathrm{nmol} / \mathrm{l}$ for SHBG; and $6.4 \%$ at $2.3 \mathrm{IU} / \mathrm{l}$ and $5.8 \%$ at $19 \mathrm{IU} / \mathrm{l}$ for LH. The working ranges of the assays were $0.7-55 \mathrm{nmol} / \mathrm{l}$ for testosterone, $2-180 \mathrm{nmol} / \mathrm{l}$ for SHBG and 0.1-200 IU/l for LH. The normal ranges for these assays in men are $8-35 \mathrm{nmol} / \mathrm{l}$ for testosterone, $10-70 \mathrm{nmol} / \mathrm{l}$ for SHBG and 1-8 IU/l for LH. Free testosterone, the fraction not bound to SHBG or albumin, was estimated using mass action equations (21). The few men with undetectable results were assigned the lower limit of the working range. Serum glucose, LDL, HDL, total cholesterol and triglycerides were assayed using a Roche Hitachi 917 analyser (Roche Diagnostic GmbH).

\section{Cohort for assessment of IHD events}

Of the 4249 men providing sera at W2, testosterone and LH were successfully assayed in 4165 and SHBG in 4162. Of these, we excluded men with prostate cancer or who had undergone orchidectomy, and those receiving anti-androgens, GnRH analogues or testosterone therapy, leaving 3638 men (including three without SHBG). Of these 3638 men, one subsequently withdrew from the study, leaving 3637 participants for analysis.

\section{Assessment of morbidity and mortality}

We assessed morbidity and mortality via the Western Australian Data Linkage System (WADLS), which provides electronic linkage to the state's population health data collections (22). WADLS comprises records from the death registry, cancer registry and hospital morbidity data system (which includes all separations for public and private hospitals in the state dating from 1970). At the time of linkage, records up to 31 December 2008 were considered complete. As we could not be certain that hospital admissions were fully reported beyond this date, we truncated our analysis at this point.

\section{IHD morbidity}

Hospital admissions after W2 were captured from WADLS morbidity data. Admissions in which the ICD-10 coded 
primary diagnosis was I20 (angina pectoris), I21 (acute myocardial infarction), I22 (subsequent myocardial infarction), I23 (certain current complications following acute myocardial infarction), I24 (other acute IHDs) or I25 (chronic IHD), or in which a coronary revascularisation procedure was performed, were considered IHD events. Revascularisation procedures were identified with ICD-10 Australian Modification (ICD-10-AM) codes from blocks 669-681.

\section{IHD mortality}

Primary cause of death was ascertained from WADLS mortality data. This dataset contains both the original death certificate and ICD codes generated from these data and other sources by the Australian Bureau of Statistics (ABS). For the final year of deaths (2008), ABS coding was not yet available. These deaths were coded by Z H and reviewed by B B Y and P E N. Deaths in which IHD appeared in the text of part 1 of the death certificate (e.g. acute myocardial infarction, atherosclerotic heart disease and chronic IHD) were considered IHD deaths. For previous years, records containing ICD-10 codes in the range I21-I25 were flagged as cases.

\section{Assessment of prevalent IHD}

Men with pre-existing IHD were identified from selfreported questionnaire data at $\mathrm{W} 1$ and $\mathrm{W} 2$ and from WADLS hospital records flagged with the ICD-10/ICD10-AM codes given previously, or with ICD-8, ICD-9 or ICD-9-CM diagnosis codes 410-414, or with Code of Surgical Operations (COSO) procedure code 304, International Classification of Procedures in Medicine (ICPM) codes 5-360 to 5-363, or ICD-9-CM procedure code 36.x.

\section{Other items of interest}

Height (in centimetres), weight (in kilograms) and blood pressure were measured at W1 and W2. Questionnaire data at W1 and W2 and biochemical assessment data at W2 were used to identify men with dyslipidaemia or diabetes. Questionnaire and clinical data at W1 and W2 were used to identify men with hypertension. Men were asked about tobacco use at both time points. As illness may reduce testosterone levels, we performed adjustments for medical comorbidity with Charlson's weighted comorbidity index (23). Hospital morbidity records from 1990 to W2 were used to build this measure.

\section{Statistical analysis}

The statistical package Stata, version 11.1, was used to analyse the data (StataCorp, 2010). Pearson's $\chi^{2}$ test was used to assess associations in categorical variables between groups. For continuous variables, $t$-tests or Mann-Whitney $U$ tests were used to assess normal and non-normal data respectively. To explore whether the risk of experiencing an IHD event differed by hormone level, we calculated age-standardised rates for each quintile of the hormones via the direct method, using the age distribution of the HIMS cohort at the time of blood sampling. Cox proportional hazard models were used to test associations between hormone levels and IHD events (hospital admission and/or death). Hormonal parameters were entered into the models as Z-scores, placing them on a common metric-free scale. Hazard ratios (HR) reflect the effect of a one s.D. increase in hormone level. Adjustments were made for age, waist:hip ratio, hypertension, dyslipidaemia, Charlson's index, smoking, diabetes and prevalent IHD. We adjusted for waist:hip ratio rather than other measures of obesity, as it may be the best predictor of IHD mortality (24). Assessment of the Schoenfeld residuals confirmed the proportional hazards assumption. All tests were two sided, and $P$ values $<0.05$ were considered statistically significant.

\section{Results}

Mean duration of follow-up was 5.1 years (range 0.1-7.2 years). During this period, 618 men (17.0\%) experienced an IHD event (hospital admission or death), of which 160 were fatal. There were 605 deaths from all causes; the proportion due to IHD was therefore $26.4 \%$ (95\% confidence interval (CI) 23.0, 30.2\%).

\section{Characteristics of men experiencing an IHD event}

Baseline demographic, biochemical and clinical characteristics of men who did and did not experience an event are shown in Table 1. Men experiencing an event were older, had lower total and free testosterone levels and higher LH levels, and were more likely to have established risk factors for IHD such as dyslipidaemia and hypertension. A larger proportion of these men had experienced a previous non-fatal IHD event.

\section{IHD events by quintiles of hormones}

Age-standardised event rates by quintiles of hormones are given in Table 2. Rates were slightly lower across increasing quintiles of total and free testosterone, and higher across increasing quintiles of LH, but this reached statistical significance only for $\mathrm{LH}$.

\section{Hormonal associations with IHD events}

As illustrated in Fig. 1, total testosterone and LH levels appeared to predict IHD events in a graded manner, with lower quintiles of total testosterone and higher quintiles of $\mathrm{LH}$ associated with reduced event-free 
Table 1 Baseline demographic, biochemical and clinical characteristics of men who did and did not experience an IHD event (fatal and non-fatal). The data is expressed either as mean \pm S.D. or as $n(\%)$.

\begin{tabular}{lccr}
\hline Variable & $\begin{array}{c}\text { No IHD event } \\
(n=3019)\end{array}$ & $\begin{array}{c}\text { IHD event } \\
(n=618)\end{array}$ & $\boldsymbol{P}$ value \\
\hline Age (years) & $76.8 \pm 3.5$ & $77.9 \pm 3.8$ & $<0.001$ \\
WHR & $0.97 \pm 0.1$ & $0.98 \pm 0.1$ & $<0.001$ \\
T testosterone (nmol/I) & $15.5 \pm 5.7$ & $14.9 \pm 5.3$ & 0.013 \\
F testosterone (pmol/l) & $280 \pm 99$ & $267 \pm 83$ & 0.002 \\
SHBG (nmol/l) & $42.4 \pm 16.4$ & $42.7 \pm 18.0$ & 0.599 \\
LH (IU//) & $5.6 \pm 4.9$ & $6.5 \pm 6.7$ & 0.004 \\
Hypertension & $2286(75.7)$ & $492(79.6)$ & 0.038 \\
Dyslipidaemia & $2241(74.2)$ & $505(81.7)$ & $<0.001$ \\
Diabetes mellitus & $450(14.9)$ & $123(19.9)$ & 0.002 \\
Smoking status & & & 0.171 \\
Never smoked & $1026(34.0)$ & $190(30.7)$ & \\
Ex-smoker & $1823(60.4)$ & $398(64.4)$ & \\
Current smoker & $170(5.6)$ & $30(4.9)$ & \\
Charlson's index & & & \\
0 & $1895(62.8)$ & $264(42.7)$ & \\
1-2 & $790(26.2)$ & $229(37.1)$ & \\
3-4 & $230(7.6)$ & $87(14.1)$ & \\
$\geq 5$ & $104(3.4)$ & $38(6.2)$ & \\
Prevalent IHD & $840(27.8)$ & $364(58.9)$ & $<0.001$ \\
\hline
\end{tabular}

IHD, ischaemic heart disease; WHR, waist-hip ratio; T, Total; F, Free.

survival. Compared with the highest quintile, free testosterone levels in the lowest quintile also appeared to be associated with reduced survival. No association was apparent for SHBG.

These associations were tested with Cox proportional hazard models (Table 3). In univariate analyses, higher levels of total testosterone $(\mathrm{HR}=0.89 ; 95 \%$ CI 0.82 , 0.97 ) and free testosterone (HR $=0.86 ; 95 \%$ CI 0.79 , 0.94) were associated with fewer IHD events. These associations were maintained after adjustment for age and waist:hip ratio but did not persist after adjustment for prevalent IHD or other risk factors. In both univariate $(\mathrm{HR}=1.15 ; 95 \% \mathrm{CI} 1.08,1.22)$ and full multivariate analyses ( $\mathrm{HR}=1.08 ; 95 \%$ CI $1.01,1.15)$, higher LH levels were associated with reduced eventfree survival. Performing additional adjustment for total or free testosterone did not substantially alter the association between LH and IHD (data not shown). SHBG was not associated with IHD events.

\section{Hormonal associations with IHD mortality}

In univariate analyses, higher free testosterone levels were associated with reduced mortality from IHD $(\mathrm{HR}=0.76 ; 95 \%$ CI $0.63,0.92)$. This association was maintained after adjustment for age and waist:hip ratio, but not after adjustment for prevalent IHD or other risk factors. A univariate association was also observed between higher SHBG levels and IHD mortality $(\mathrm{HR}=1.17,95 \%$ CI $1.02,1.34)$ but did not persist after adjustment for age or other covariates. Higher LH levels were associated with mortality from IHD in both univariate $(\mathrm{HR}=1.26 ; 95 \% \mathrm{CI} 1.16,1.38)$ and full multivariate $(\mathrm{HR}=1.14 ; 95 \%$ CI $1.04,1.25)$ models. Performing additional adjustment for total or free testosterone did not substantially alter the association between LH and IHD mortality (data not shown).

\section{Assessment of reverse causality}

To explore the possibility of reverse causality, we performed a sensitivity analysis in which we examined the predictors of IHD events in men with $(n=1204)$ and without $(n=2433)$ prevalent IHD. As expected with reduced power, the adjusted association between LH and IHD events was attenuated but remained essentially unchanged in men with $(\mathrm{HR}=1.08 ; 95 \%$ CI 0.99 , $1.17)$ and without $(\mathrm{HR}=1.08 ; 95 \%$ CI $0.95,1.22)$ prevalent IHD. Although we attempted to control for medical comorbidity, the possibility remains that illness at the time of blood sampling may have affected sex hormone levels. We therefore repeated our analyses after excluding 134 men who died within 2 years of blood collection. After these exclusions, LH levels continued to predict IHD mortality $(\mathrm{HR}=1.18 ; 95 \%$ CI 1.06, 1.31) and events ( $\mathrm{HR}=1.09 ; 95 \%$ CI 1.02, 1.17).

\section{IHD mortality and events by gonadal status}

The association observed between IHD events and LH, but not total or free testosterone, could still indicate a

Table 2 Ischaemic heart disease events (fatal and non-fatal) by quintiles of hormones. Age-standardised rate is per 1000 personyears.

\begin{tabular}{lcccc}
\hline Hormone & $\begin{array}{c}\text { Events/ } \\
\text { men at risk } \\
\text { quintile }\end{array}$ & $\begin{array}{c}\text { Follow-up } \\
\text { person- } \\
\text { years }\end{array}$ & $\begin{array}{c}\text { Age- } \\
\text { standardised } \\
\text { rate }\end{array}$ & $\mathbf{9 5 \% ~ C l}$ \\
\hline Testosterone & & & & \\
1 (lowest) & $130 / 715$ & 3295 & 40.7 & $33.7,47.7$ \\
2 & $131 / 727$ & 3406 & 38.7 & $32.0,45.4$ \\
3 & $127 / 737$ & 3569 & 34.4 & $28.4,40.5$ \\
4 & $122 / 723$ & 3462 & 34.8 & $28.6,41.0$ \\
5 (highest) & $108 / 735$ & 3547 & 30.5 & $24.5,36.4$ \\
Free testosterone & & & & \\
1 (lowest) & $142 / 721$ & 3312 & 43.2 & $35.8,50.5$ \\
2 & $118 / 718$ & 3432 & 33.7 & $27.5,39.8$ \\
3 & $125 / 732$ & 3562 & 33.8 & $27.8,39.8$ \\
4 & $121 / 730$ & 3455 & 35.7 & $29.2,42.1$ \\
5 (highest) & $112 / 733$ & 3500 & 32.7 & $26.5,39.0$ \\
SHBG & & & & \\
1 (lowest) & $123 / 723$ & 3336 & 39.3 & $31.9,46.6$ \\
2 & $122 / 729$ & 3436 & 35.8 & $29.4,42.1$ \\
3 & $132 / 727$ & 3501 & 38.5 & $31.8,45.1$ \\
4 & $125 / 726$ & 3470 & 35.6 & $29.1,42.0$ \\
5 (highest) & $116 / 729$ & 3520 & 29.1 & $23.7,34.6$ \\
LH & & & & \\
1 (lowest) & $104 / 724$ & 3462 & 30.0 & $24.2,35.9$ \\
2 & $116 / 729$ & 3478 & 35.7 & $29.1,42.3$ \\
3 & $131 / 728$ & 3499 & 36.2 & $30.0,42.5$ \\
4 & $118 / 727$ & 3465 & 33.8 & $27.6,40.1$ \\
5 (highest) & $149 / 729$ & 3374 & 43.6 & $36.1,51.1$ \\
\hline
\end{tabular}

$\mathrm{Cl}$, confidence interval. 

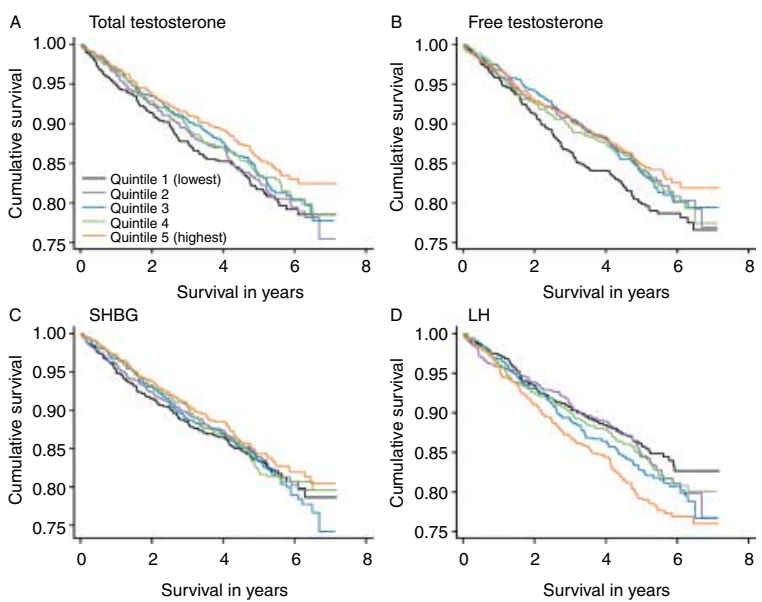

Figure 1 Kaplan-Meier survival curves showing associations between ischaemic heart disease events (fatal and non-fatal) and quintiles of total testosterone (A), free testosterone (B), SHBG (C) and $\mathrm{LH}(\mathrm{D})$.

relationship between testosterone and IHD, as LH levels might better reflect androgen status in older men. To investigate this hypothesis, we stratified men by categories of hypogonadism using previously published Australian criteria (25) and examined IHD events in each group (Table 4).

After 5 years, the proportion of men experiencing an event did not differ between those with normal hormone levels and those classified as having hypogonadotrophic hypogonadism or Leydig cell impairment. However, the proportion of men with hypergonadotrophic hypogonadism who experienced a new event was double that of the normal group (35.0 vs $15.8 \%$ ). There was also no difference in IHD deaths between normal men and men with hypogonadotrophic hypogonadism. However, mortality due to IHD in those with Leydig cell impairment $(8.6 \%)$ or hypergonadotrophic hypogonadism $(11.5 \%)$ was at least twice that of normal men $(3.4 \%)$ and men with hypogonadotrophic hypogonadism $(3.9 \%)$.

\section{Discussion}

In this prospective study of community-dwelling men aged 70 years and older, higher LH levels were associated with greater likelihood of experiencing an IHD event. This association was maintained after adjustment for potential confounders and established cardiovascular risk factors. To our knowledge, this is the first time that LH levels have been identified as a marker of IHD risk in older men.

Relatively few prospective studies have explored the relationship between endogenous sex hormones and IHD in elderly men. Most have focused on cardiovascular disease generally and have comprised varying sample sizes and age ranges. Khaw et al. (16) reported an association between low total testosterone levels and all-cause, cardiovascular and IHD mortality in a nested case-control analysis comprising 2314 men aged

Table 3 Cox proportional hazard models exploring hormone levels and associations with subsequent IHD events (fatal and non-fatal) and mortality.

\begin{tabular}{|c|c|c|c|c|c|c|}
\hline \multirow[b]{3}{*}{ Variable } & \multicolumn{6}{|c|}{ Outcome } \\
\hline & \multicolumn{3}{|c|}{ IHD event } & \multicolumn{3}{|c|}{ IHD mortality } \\
\hline & $\mathrm{HR}$ & $95 \% \mathrm{Cl}$ & $P$ value & HR & $95 \% \mathrm{Cl}$ & $P$ value \\
\hline \multicolumn{7}{|c|}{ Total testosterone } \\
\hline Model 1 & 0.89 & $0.82,0.97$ & 0.007 & 0.86 & $0.73,1.02$ & 0.082 \\
\hline Model 2 & 0.92 & $0.84,0.99$ & 0.042 & 0.87 & $0.74,1.04$ & 0.121 \\
\hline Model 3 & 0.94 & $0.87,1.02$ & 0.145 & 0.91 & $0.77,1.08$ & 0.273 \\
\hline Model 4 & 0.96 & $0.88,1.04$ & 0.321 & 0.93 & $0.78,1.10$ & 0.374 \\
\hline \multicolumn{7}{|c|}{ Free testosterone } \\
\hline Model 1 & 0.86 & $0.79,0.94$ & 0.001 & 0.76 & $0.63,0.92$ & 0.004 \\
\hline Model 2 & 0.90 & $0.83,0.99$ & 0.022 & 0.82 & $0.69,0.99$ & 0.035 \\
\hline Model 3 & 0.93 & $0.85,1.01$ & 0.086 & 0.86 & $0.72,1.03$ & 0.098 \\
\hline Model 4 & 0.94 & $0.87,1.02$ & 0.167 & 0.88 & $0.74,1.05$ & 0.164 \\
\hline \multicolumn{7}{|l|}{ SHBG } \\
\hline Model 1 & 1.01 & $0.93,1.09$ & 0.831 & 1.17 & $1.02,1.34$ & 0.025 \\
\hline Model 2 & 1.00 & $0.92,1.09$ & 0.986 & 1.12 & $0.96,1.29$ & 0.139 \\
\hline Model 3 & 1.00 & $0.92,1.09$ & 0.984 & 1.12 & $0.97,1.28$ & 0.117 \\
\hline Model 4 & 1.01 & $0.93,1.10$ & 0.740 & 1.12 & $0.97,1.29$ & 0.109 \\
\hline \multicolumn{7}{|l|}{ LH } \\
\hline Model 1 & 1.15 & $1.08,1.22$ & $<0.001$ & 1.26 & $1.16,1.38$ & $<0.001$ \\
\hline Model 2 & 1.11 & $1.04,1.19$ & 0.001 & 1.21 & $1.10,1.34$ & $<0.001$ \\
\hline Model 3 & 1.09 & $1.02,1.16$ & 0.012 & 1.17 & $1.07,1.29$ & 0.001 \\
\hline Model 4 & 1.08 & $1.01,1.15$ & 0.022 & 1.14 & $1.04,1.25$ & 0.006 \\
\hline
\end{tabular}

Model 1, univariate; Model 2, adjusted for age and waist:hip ratio; Model 3, model 2+ prevalent IHD; Model 4, model 3+ hypertension, dyslipidaemia, smoking status, diabetes and Charlson's weighted co-morbidity index. Hazard ratios indicate the effect of a one s.D. increase in hormone level. $\mathrm{Cl}$, confidence interval; IHD, ischaemic heart disease; HR, hazard ratio. 
Table 4 Five-year risk of ischaemic heart disease events (fatal and non-fatal) and mortality by categories of hormone status. Table does not include the data of 97 men with total testosterone $>15 \mathrm{nmol} / \mathrm{l}$ and $\mathrm{LH}>12 \mathrm{lU} / \mathrm{l}$.

\begin{tabular}{|c|c|c|c|c|c|c|}
\hline \multirow[b]{2}{*}{ Category } & \multicolumn{3}{|c|}{ IHD event } & \multicolumn{3}{|c|}{ IHD mortality } \\
\hline & $\%$ & $95 \% \mathrm{Cl}$ & $P$ value & $\%$ & $95 \% \mathrm{Cl}$ & $P$ value \\
\hline $\begin{array}{l}\text { Normal }(n=3225) \\
\text { Testosterone } \geq 8 \mathrm{nmol} / \mathrm{I} \\
\text { LH } \leq 12 \mathrm{IU} / \mathrm{I}\end{array}$ & 15.8 & $14.5,17.2$ & - & 3.4 & $2.8,4.1$ & - \\
\hline $\begin{array}{l}\text { Hypogonadotrophic hypogonadism }(n=133) \\
\text { Testosterone }<8 \mathrm{nmol} / / \\
\text { LH } \leq 12 \mathrm{IU} / \mathrm{l}\end{array}$ & 21.0 & $14.9,29.1$ & 0.069 & 3.9 & $1.6,9.0$ & 0.599 \\
\hline $\begin{array}{l}\text { Leydig cell impairment }(n=126) \\
\text { Testosterone } 8-15 \mathrm{nmol} / \mathrm{I} \\
\text { LH }>12 \mathrm{IU} / \mathrm{l}\end{array}$ & 19.6 & $13.4,28.0$ & 0.113 & 8.6 & $4.7,15.3$ & $<0.001$ \\
\hline $\begin{array}{l}\text { Hypergonadotrophic hypogonadism }(n=56) \\
\text { Testosterone }<8 \mathrm{nmol} / / \\
\text { LH }>12 \mathrm{IU} / \mathrm{l}\end{array}$ & 35.0 & $23.6,49.9$ & 0.001 & 11.5 & $5.3,23.8$ & 0.010 \\
\hline
\end{tabular}

$P$ values are for log-rank test between men with normal hormone status and categories of hypogonadism.

42-78 years. Compared with men with total testosterone levels in the highest quartile, men in the lowest quartile were almost twice as likely to have died from IHD. Low testosterone levels were also associated with cardiovascular and all-cause mortality in the Rancho Bernardo Study (26). In this sample of 794 men aged 50-91 years, a graded increase in risk across decreasing quartiles of both total and bioavailable (non-SHBG bound) testosterone was observed. We have also previously reported associations between low free testosterone and incident stroke and transient ischaemic attack, and prevalent AAA in this cohort (10, 27). Higher LH levels were also associated with AAA in the latter analysis.

Studies focussing on markers of atherosclerosis, rather than on cardiovascular events, have also reported associations between low testosterone levels and development or worsening of the disease. Hougaku et al. (28) found that total testosterone levels were inversely associated with carotid stiffness in longitudinal analyses of 206 men aged 33-95 years. Hak et al. (29) measured calcification of the abdominal aorta in 504 men aged 55-89 years. Men with total or bioavailable testosterone levels in the highest, compared with the lowest tertile, were less likely to have severe atherosclerosis at baseline and were less likely to develop or show progression of the condition after a follow-up period of 6.5 years.

However, in the Tromsø study, comprising 1568 men with a mean age of 59 years, neither total nor free testosterone was associated with cardiovascular or IHD deaths, although lower free testosterone levels were associated with all-cause mortality (17). A smaller Finnish study of 187 men aged 71-72 years found that low total testosterone was associated with all-cause but not cardiovascular mortality (30). Price et al. (31) found that neither oestradiol nor total or free testosterone levels were significantly associated with peripheral arterial disease in a nested case-control study of 81 elderly men. The Framingham Heart Study of 2084 middle-aged men was also unable to demonstrate an association between testosterone levels and cardiovascular events but observed a protective effect for oestradiol (32). An apparent adverse effect of higher testosterone levels has also been reported. In a subset of the Massachusetts Male Aging Study comprising 1686 men aged 40-70 years, there was a graded increase in the risk of IHD mortality across increasing quintiles of free testosterone (18).

Interventional data are also conflicting. Intravenous testosterone increased the time to exercise-induced myocardial ischaemia in 14 men with coronary artery disease (33) and increased flow-mediated reactivity of the brachial artery in a small crossover study of 22 men with IHD (34). In another crossover study of 22 men with low testosterone randomised to oral testosterone undecanoate or placebo for 8 weeks, testosterone improved measures of arterial stiffness, though did not improve angina symptoms (35). In contrast, a recent randomised placebo-controlled trial of transdermal testosterone in 209 older men with low testosterone and mobility limitations was terminated early due to safety concerns (36). Adverse cardiovascular events were experienced by 23 men in the treatment group, compared with five in the placebo group. However, the majority of participants were hypertensive, which may have been exacerbated by the high testosterone dose used. Another recent study of 50 middle-aged hypogonadal men randomised to intramuscular testosterone undecanoate or placebo for 24 months did not report any cardiovascular safety concerns (37).

We propose three hypotheses to explain the association between higher LH levels and greater IHD events: i) androgen deficiency is detrimental to the cardiovascular system, but LH better reflects prevailing testosterone levels; and/or ii) LH has an independent effect on the cardiovascular system, with elevated levels being harmful; or iii) elevated LH is not directly involved in the pathogenesis of IHD but is rather an epiphenomenon of another disease process. The first hypothesis is 
supported by evidence of testosterone's immunemodulating properties. In both in vitro and in vivo studies, testosterone reduces inflammation and production of pro-inflammatory cytokines, which are considered to play a role in the development of atherosclerosis $(12,38)$. The normal endothelium is permeable to LDL, which accumulates in the arterial wall, provoking an inflammatory response and the eventual formation of an atherosclerotic plaque. Continued production of inflammatory cytokines compromises the stability of the plaque, leading to erosion or rupture, and an acute coronary syndrome (9). Testosterone also has anti-thrombotic actions and an inverse relationship with fibrinogen levels (38). A role in lipid metabolism is also hypothesised. Androgen deficiency is associated with an atherogenic lipid profile (11), while testosterone therapy generally lowers total cholesterol and LDL, although decreases in HDL are also reported (39). Animal and human studies also suggest direct vasoactive properties. Dose-dependent vasodilatory effects are observed in the presence of androgen receptor $(\mathrm{AR})$ antagonists and in testicular feminised mice $(40,41)$. Alternatively, some of the favourable effects attributed to testosterone may be at least partly due to oestradiol, which is also thought to have beneficial actions. Aromatase deficiency in males is associated with a range of metabolic disturbances and increased risk of cardiovascular disease, despite adequate testosterone levels (42). Nonetheless, while testosterone supplementation has been shown to reduce atherosclerosis in both orchidectomised wild-type and AR knock-out mice fed a high-fat diet, efficacy was superior in mice with a functional AR, supporting an independent role for testosterone (43).

However, when we stratified by categories of hypogonadism, we observed a difference in IHD events, with men with hypergonadotrophic hypogonadism more likely to experience an event than those with hypogonadotrophic hypogonadism. This could suggest a more complicated relationship, with LH directly involved in the pathogenesis of IHD, perhaps mediated via the $\mathrm{LH}$ receptor (LHR). Although originally thought to be present only in gonadal cells, the LHR has since been identified in extragonadal sites (44), including smooth muscle and vascular tissue $(45,46)$. Berndt et al. (45) reported that the expression of LHR was associated with endothelial cell proliferation in the mouse aorta. LH might therefore theoretically exert a direct effect on the heart or associated vascular structures. In particular, the increased IHD mortality in men with low normal testosterone and elevated LH suggests that it is not the absolute level of testosterone that determines risk but rather the degree of hypothalamic-pituitary-gonadal axis disruption. Leydig cell impairment (compensated hypogonadism) has been postulated as a distinct syndrome $(25,47)$, but this is the first time that an important clinical consequence has been observed. Therefore, our results suggest that assessment of androgen deficiency in men should include risk stratification based on both testosterone and LH levels.

Alternatively, it is possible that our observations reflect underlying disease, with illness directly reducing testosterone production at the testicular level or indirectly via suppression of gonadotrophins. However, the latter is unlikely given that we found an association between IHD and hypergonadotrophic hypogonadism. Furthermore, we assessed and performed adjustments for medical comorbidity. Nonetheless, the possibility of residual confounding cannot be entirely eliminated, highlighting the difficulty of establishing causality in observational analyses.

Strengths of our study include the large, populationbased sample, relatively narrow age range compared with previous studies, and use of electronic record linkage to capture endpoints. The latter is a key strength of this study, facilitating complete ascertainment of hospital admissions and mortality, and may explain why we found an association while other studies have not. Additionally, we limited our endpoints to a small and precisely defined range, compared with other studies that have included a disparate class of cardiovascular disorders (48). Limitations of our study include collection of a single blood sample and use of the Vermeulen method to calculate free testosterone. However, this method is widely used in other studies and is considered to provide a reasonable estimate of actual levels. We did not have the resources to collect additional samples or to assay other hormones such as oestradiol. We also cannot exclude the possibility that some men may have been misdiagnosed or their admissions or death certificates coded imprecisely. For example, the ICD contains a number of ill-defined cardiovascular disease codes, which are used frequently in some countries. However, coding of mortality is considered precise in Australia (49), and the similarity of our findings with regard to mortality and both fatal and non-fatal events is reassuring. Additionally, validation studies of the WADLS have established very high consistency between clinical coding and medical records (50).

In summary, this study suggests that higher LH levels are associated with increased IHD events in men. The possibility of an independent role for $\mathrm{LH}$ in the pathogenesis of IHD requires further investigation. Although not statistically significant, there appeared to be a graded relationship between decreasing testosterone levels and increasing risk, suggesting that androgen deficiency could be involved in the aetiology of IHD. A graded rather than threshold effect suggests that risk may not be confined to men with the very lowest levels. However, given conflicting data from other observational studies and safety concerns raised by a recent trial, it would be premature to suggest testosterone therapy for the prevention of IHD. Further studies are warranted, with particular emphasis on men with elevated LH in addition to those with low testosterone levels. 


\section{Declaration of interest}

The authors declare that there is no conflict of interest that could be perceived as prejudicing the impartiality of the research reported.

\section{Funding}

This work was supported by the National Health and Medical Research Council of Australia (grant numbers 279408, 379600, 403963, 513823 and 634492) and from the MBF Foundation of Australia (grant number DS 080608). Z Hyde is supported by a NHMRC Biomedical Postgraduate Scholarship. Hormone assays were funded by a Clinical Investigator Award to B B Yeap from the Sylvia and Charles Viertel Charitable Foundation, New South Wales, Australia, and by a research grant to $\mathrm{P}$ Chubb from the Fremantle Hospital Medical Research Foundation, Western Australia.

\section{Acknowledgements}

The authors thank Tricia Knox and the staff of the Department of Biochemistry, PathWest, Royal Perth and Fremantle Hospitals, Western Australia, for their assistance in performing the hormone assays, and Peter Feddema from DPC-Biomediq, Australia, for his assistance with sourcing hormone assay kits and reagents. We thank the staff and management of Shenton Park Hospital for providing space in which to conduct follow-up clinics. We especially thank all the men who participated in the Western Australian Abdominal Aortic Aneurysm Program and the Health in Men Study, and the research assistants who helped with data collection.

\section{References}

1 World Health Organization. The Global Burden of Disease: 2004 Update. Geneva, Switzerland: WHO, 2008.

2 Tunstall-Pedoe $\mathrm{H}$, Kuulasmaa $\mathrm{K}$, Mähönen $\mathrm{M}$, Tolonen $\mathrm{H}$, Ruokokoski E \& Amouyel P. Contribution of trends in survival and coronary-event rates to changes in coronary heart disease mortality: 10-year results from 37 WHO MONICA project populations. Monitoring trends and determinants in cardiovascular disease. Lancet 1999353 1547-1557. (doi:10.1016/ S0140-6736(99)04021-0)

3 Barrett-Connor E. Sex differences in coronary heart disease. Why are women so superior? The 1995 Ancel Keys Lecture. Circulation 199795 252-264.

4 Bailey MS \& Curtis AB. The effects of hormones on arrhythmias in women. Current Women's Health Reports 20022 83-88.

5 Bidoggia H, Maciel JP, Capalozza N, Mosca S, Blaksley EJ, Valverde E, Bertran G, Arini P, Biagetti MO \& Quinteiro RA. Sex differences on the electrocardiographic pattern of cardiac repolarization: possible role of testosterone. American Heart Journal 2000140 678-683. (doi:10.1067/mhj.2000.109918)

6 Fülöp L, Bányász T, Szabó G, Tóth IB, Bíró T, Lôrincz I, Balogh A, Petô K, Mikó I \& Nánási PP. Effects of sex hormones on ECG parameters and expression of cardiac ion channels in dogs. Acta Physiologica $2006 \mathbf{1 8 8}$ 163-171. (doi:10.1111/j.1748-1716. 2006.01618.x)

7 Kienitz T \& Quinkler M. Testosterone and blood pressure regulation. Kidney and Blood Pressure Research 200831 71-79. (doi:10.1159/000119417)

8 Crook D \& Seed M. Endocrine control of plasma lipoprotein metabolism: effects of gonadal steroids. Baillière's Clinical Endocrinology and Metabolism 19904 851-875. (doi:10.1016/ S0950-351X(05)80082-5)

9 Jones TH \& Saad F. The effects of testosterone on risk factors for, and the mediators of the atherosclerotic process. Atherosclerosis 2009 207 318-327. (doi:10.1016/j.atherosclerosis.2009.04.016)

10 Yeap BB, Hyde Z, Norman PE, Chubb SAP \& Golledge J. Associations of total testosterone, sex hormone-binding globulin, calculated free testosterone, and luteinizing hormone with prevalence of abdominal aortic aneurysm in older men. Journal of Clinical Endocrinology and Metabolism 201095 1123-1130. (doi:10.1210/jc.2009-1696)

11 Channer KS \& Jones TH. Cardiovascular effects of testosterone: implications of the "male menopause"? Heart 200389 121-122. (doi:10.1136/heart.89.2.121)

12 Malkin CJ, Pugh PJ, Jones RD, Kapoor D, Channer KS \& Jones TH. The effect of testosterone replacement on endogenous inflammatory cytokines and lipid profiles in hypogonadal men. Journal of Clinical Endocrinology and Metabolism 200489 3313-3318. (doi:10.1210/jc.2003-031069)

13 Mancini A, Leone E, Festa R, Grande G, Silvestrini A, de Marinis L, Pontecorvi A, Maira G, Littarru GP \& Meucci E. Effects of testosterone on antioxidant systems in male secondary hypogonadism. Journal of Andrology 200829 622-629. (doi:10.2164/ jandrol.107.004838)

14 Shabsigh R, Katz M, Yan G \& Makhsida N. Cardiovascular issues in hypogonadism and testosterone therapy. American Journal of Cardiology 200596 67M-72M. (doi:10.1016/j.amjcard.2005. 10.009)

15 Harman SM, Metter EJ, Tobin JD, Pearson J \& Blackman MR. Longitudinal effects of aging on serum total and free testosterone levels in healthy men. Journal of Clinical Endocrinology and Metabolism 200186 724-731. (doi:10.1210/jc.86.2.724)

16 Khaw KT, Dowsett M, Folkerd E, Bingham S, Wareham N, Luben R, Welch A \& Day N. Endogenous testosterone and mortality due to all causes, cardiovascular disease, and cancer in men: European Prospective Investigation Into Cancer in Norfolk (EPIC-Norfolk) Prospective Population Study. Circulation 2007116 2694-2701. (doi:10.1161/CIRCULATIONAHA.107.719005)

17 Vikan T, Schirmer H, Njølstad I \& Svartberg J. Endogenous sex hormones and the prospective association with cardiovascular disease and mortality in men: the Tromsø study. European Journal of Endocrinology 2009161 435-442. (doi:10.1530/EJE09-0284)

18 Araujo AB, Kupelian V, Page ST, Handelsman DJ. Bremner WJ \& McKinlay JB. Sex steroids and all-cause and cause-specific mortality in men. Archives of Internal Medicine $2007 \mathbf{1 6 7}$ 1252-1260. (doi:10.1001/archinte.167.12.1252)

19 Norman PE, Flicker L, Almeida OP, Hankey GJ. Hyde Z \& Jamrozik K. Cohort profile: the Health in Men Study (HIMS). International Journal of Epidemiology 200938 48-52. (doi:10. 1093/ije/dyn041)

20 Yeap BB, Almeida OP, Hyde Z, Norman PE, Chubb SAP, Jamrozik K \& Flicker L. In men older than 70 years, total testosterone remains stable while free testosterone declines with age. The Health in Men Study. European Journal of Endocrinology 2007156 585-594. (doi:10.1530/EJE-06-0714)

21 Vermeulen A, Verdonck L \& Kaufman JM. A critical evaluation of simple methods for the estimation of free testosterone in serum. Journal of Clinical Endocrinology and Metabolism $1999 \mathbf{8 4}$ 3666-3672. (doi:10.1210/jc.84.10.3666)

22 Holman CD, Bass AJ, Rouse IL \& Hobbs MS. Population-based linkage of health records in Western Australia: development of a health services research linked database. Australian and New Zealand Journal of Public Health 199923 453-459. (doi:10.1111/ j.1467-842X.1999.tb01297.x)

23 Charlson ME, Pompei P, Ales KL \& MacKenzie CR. A new method of classifying prognostic comorbidity in longitudinal studies: development and validation. Journal of Chronic Diseases 198740 373-383. (doi:10.1016/0021-9681(87)90171-8)

24 Welborn TA, Dhaliwal SS \& Bennett SA. Waist-hip ratio is the dominant risk factor predicting cardiovascular death in Australia. Medical Journal of Australia $2003 \mathbf{1 7 9} 580-585$.

25 Conway AJ, Handelsman DJ, Lording DW, Stuckey B \& Zajac JD. Use, misuse and abuse of androgens. The Endocrine Society of Australia consensus guidelines for androgen prescribing. Medical Journal of Australia 2000172 220-224. 
26 Laughlin GA, Barrett-Connor E \& Bergstrom J. Low serum testosterone and mortality in older men. Journal of Clinical Endocrinology and Metabolism 200893 68-75. (doi:10.1210/jc. 2007-1792)

27 Yeap BB, Hyde Z, Almeida OP, Norman PE, Chubb SAP, Jamrozik K, Flicker L \& Hankey GJ. Lower testosterone levels predict incident stroke and transient ischemic attack in older men. Journal of Clinical Endocrinology and Metabolism $2009942353-2359$. (doi:10.1210/jc.2008-2416)

28 Hougaku H, Fleg JL, Najjar SS, Lakatta EG, Harman SM, Blackman MR \& Metter EJ. Relationship between androgenic hormones and arterial stiffness, based on longitudinal hormone measurements. American Journal of Physiology. Endocrinology and Metabolism 2006290 E234-E242. (doi:10.1152/ajpendo.00059. 2005)

29 Hak AE, Witteman JC, de Jong FH, Geerlings MI, Hofman A \& Pols HA. Low levels of endogenous androgens increase the risk of atherosclerosis in elderly men: the Rotterdam Study. Journal of Clinical Endocrinology and Metabolism $2002 \quad 87$ 3632-3639. (doi:10.1210/jc.87.8.3632)

30 Lehtonen A, Huupponen R, Tuomilehto J, Lavonius S, Arve S, Isoaho H, Huhtaniemi I \& Tilvis R. Serum testosterone but not leptin predicts mortality in elderly men. Age and Ageing 200837 461-464. (doi:10.1093/ageing/afn048)

31 Price JF, Lee AJ \& Fowkes FG. Steroid sex hormones and peripheral arterial disease in the Edinburgh Artery Study. Steroids 199762 789-794. (doi:10.1016/S0039-128X(97)00103-7)

32 Arnlöv J, Pencina MJ, Amin S, Nam BH, Benjamin EJ, Murabito JM, Wang TJ, Knapp PE, D’Agostino RB Sr, Bhasin S \& Vasan RS. Endogenous sex hormones and cardiovascular disease incidence in men. Annals of Internal Medicine 2006145 176-184.

33 Rosano G, Leonardo F, Pagnotta P, Pelliccia F, Panina G, Cerquetani E, della Monica P, Bonfigli B, Volpe M \& Chierchia S. Acute anti-ischemic effect of testosterone in men with coronary artery disease. Circulation 199999 1666-1670.

34 Ong PJ, Patrizi G, Chong WC, Webb CM, Hayward CS \& Collins P. Testosterone enhances flow-mediated brachial artery reactivity in men with coronary artery disease. American Journal of Cardiology 200085 269-272. (doi:10.1016/S0002-9149(99)00630-X)

35 Webb CM, Elkington AG, Kraidly MM, Keenan N, Pennell DJ \& Collins P. Effects of oral testosterone treatment on myocardial perfusion and vascular function in men with low plasma testosterone and coronary heart disease. American Journal of Cardiology 2008101 618-624. (doi:10.1016/j.amjcard.2007. 09.114)

36 Basaria S, Coviello AD, Travison TG, Storer TW, Farwell WR, Jette AM, Eder R, Tennstedt S, Ulloor J, Zhang A, Choong K, Lakshman KM, Mazer NA, Miciek R, Krasnoff J, Elmi A, Knapp PE, Brooks B, Appleman E, Aggarwal S, Bhasin G, Hede-Brierley L, Bhatia A, Collins L, Lebrasseur N, Fiore LD \& Bhasin S. Adverse events associated with testosterone administration. New England Journal of Medicine $2010 \quad 363 \quad 109-122 . \quad$ (doi:10.1056/ NEJMoa1000485)

37 Aversa A, Bruzziches R, Francomano D, Rosano G, Isidori AM, Lenzi A \& Spera G. Effects of testosterone undecanoate on cardiovascular risk factors and atherosclerosis in middle-aged men with late-onset hypogonadism and metabolic syndrome: results from a 24-month, randomized, double-blind, placebocontrolled study. Journal of Sexual Medicine 20107 3495-3503. (doi:10.1111/j.1743-6109.2010.01931.x)

38 Malkin CJ, Pugh PJ, Jones TH \& Channer KS. Testosterone for secondary prevention in men with ischaemic heart disease? Quarterly Journal of Medicine 200396 521-529.
39 Whitsel EA, Boyko EJ, Matsumoto AM, Anawalt BD \& Siscovick DS. Intramuscular testosterone esters and plasma lipids in hypogonadal men: a meta-analysis. American Journal of Medicine 2001111 261-269. (doi:10.1016/S0002-9343(01)00833-6)

40 Jones RD, Pugh PJ, Hall J, Channer KS \& Jones TH. Altered circulating hormone levels, endothelial function and vascular reactivity in the testicular feminised mouse. European Journal of Endocrinology 2003 148 111-120. (doi:10.1530/eje.0.1480111)

41 Jones RD, English KM, Jones TH \& Channer KS. Testosteroneinduced coronary vasodilatation occurs via a non-genomic mechanism: evidence of a direct calcium antagonism action. Clinical Science 2004107 149-158. (doi:10.1042/CS20030386)

42 Jones ME, Boon WC, Proietto J \& Simpson ER. Of mice and men: the evolving phenotype of aromatase deficiency. Trends in Endocrinology and Metabolism $2006 \quad 17$ 55-64. (doi:10.1016/ j.tem.2006.01.004)

43 Bourghardt J, Wilhelmson AS, Alexanderson C, De Gendt K, Verhoeven G, Krettek A, Ohlsson C \& Tivesten A. Androgen receptor-dependent and independent atheroprotection by testosterone in male mice. Endocrinology 2010151 5428-5437. (doi:10. 1210/en.2010-0663)

44 Rahman NA \& Rao CV. Recent progress in luteinizing hormone/ human chorionic gonadotrophin hormone research. Molecular Human Reproduction 200915 703-711. (doi:10.1093/molehr/ gap067)

45 Berndt S, Perrier d'Hauterive S, Blacher S, Pequeux C, Lorquet S, Munaut C, Applanat M, Herve MA, Lamande N, Corvol P, van den Brule F, Frankenne F, Poutanen M, Huhtaniemi I, Geenen V, Noel A \& Foidart JM. Angiogenic activity of human chorionic gonadotropin through $\mathrm{LH}$ receptor activation on endothelial and epithelial cells of the endometrium. FASEB Journal $2006 \mathbf{2 0}$ 2630-2632. (doi:10.1096/fj.06-5885fje)

46 Toth P, Li X, Rao CV, Lincoln SR, Sanfilippo JS, Spinnato JA II \& Yussman MA. Expression of functional human chorionic gonadotropin/human luteinizing hormone receptor gene in human uterine arteries. Journal of Clinical Endocrinology and Metabolism 199479 307-315. (doi:10.1210/jc.79.1.307)

47 Tajar A, Forti G, O’Neill TW, Lee DM, Silman AJ, Finn JD, Bartfai G, Boonen S, Casanueva FF, Giwercman A, Han TS, Kula K, Labrie F, Lean ME, Pendleton N, Punab M, Vanderschueren D, Huhtaniemi IT \& Wu FC. Characteristics of secondary, primary, and compensated hypogonadism in aging men: evidence from the European Male Ageing Study. Journal of Clinical Endocrinology and Metabolism 2010 95 1810-1818. (doi:10.1210/jc.2009-1796)

48 Tivesten A, Vandenput L, Labrie F, Karlsson MK, Ljunggren O, Mellström D \& Ohlsson C. Low serum testosterone and estradiol predict mortality in elderly men. Journal of Clinical Endocrinology and Metabolism 200994 2482-2488. (doi:10.1210/jc.20082650)

49 Lozano R, Murray CJL, Lopez AD \& Satoh T. Miscoding and Misclassification of Ischaemic Heart Disease Mortality. Geneva: World Health Organization, 2001.

50 Teng TH, Finn J, Hung J, Geelhoed E \& Hobbs M. A validation study: how effective is the Hospital Morbidity Data as a surveillance tool for heart failure in Western Australia? Australian and New Zealand Journal of Public Health 200832 405-407. (doi:10.1111/j.1753-6405.2008.00269.x)

Received 20 January 2011

Accepted 1 February 2011 